\title{
Signals through the Striatopallidal Indirect Pathway Stop Movements by Phasic Excitation in the Substantia Nigra
}

\author{
Hiromi Sano, ${ }^{1}$ Satomi Chiken, ${ }^{1,2}$ Takatoshi Hikida, ${ }^{3,4}$ Kazuto Kobayashi, ${ }^{5}$ and Atsushi Nambu ${ }^{1,2}$ \\ ${ }^{1}$ Division of System Neurophysiology, National Institute for Physiological Sciences, Okazaki 444-8585, Japan, ${ }^{2}$ Department of Physiological Sciences, \\ Graduate University for Advanced Studies, Okazaki 444-8585, Japan, ${ }^{3}$ Department of Research and Drug Discovery, Medical Innovation Center, Kyoto \\ University Graduate School of Medicine, Kyoto 606-8507, Japan, ${ }^{4}$ Department of Systems Biology, Osaka Bioscience Institute, Osaka 565-0874, Japan, and \\ ${ }^{5}$ Department of Molecular Genetics, Fukushima Medical University, Fukushima 960-1295, Japan
}

The striatum and subthalamic nucleus (STN) are the input stations of the basal ganglia and receive excitatory afferents from the cerebral cortex. The basal ganglia control voluntary movements through three parallel pathways mediated by the input stations: the hyperdirect pathway, which conveys direct cortical inputs to the substantia nigra pars reticulata (SNr), the output nucleus, through the STN; the direct pathway, which arises from striatal neurons expressing dopamine D1 receptors and projects to the SNr; and the indirect pathway, which arises from striatal neurons expressing dopamine D2 receptors (D2Rs) and projects indirectly to the SNr by way of the globus pallidus (GP) and STN. Our previous study showed that immunotoxin-mediated cell targeted ablation of D2R-expressing striatal neurons in mice induced motor hyperactivity. To elucidate the mechanism underlying the hyperactivity, here we examined neuronal activity in the GP and SNr. The ablation of D2R-expressing striatal neurons had little effect on spontaneous activity in the GP and SNr, but induced dramatic changes in the cortically evoked triphasic response composed of early excitation, inhibition, and late excitation in the GP and SNr (i.e., reduced inhibition in the GP, and reduced late excitation in the GP and $\mathrm{SNr}$ ). In contrast, the ablation of striatal cholinergic interneurons, which also express D2Rs, did not show such effects. Therefore, the reduction of the cortically evoked late excitation in the SNr seems to be responsible for hyperactivity. These observations suggest that phasic late excitation in the SNr through the striatopallidal indirect pathway plays a key role in stopping movements.

\section{Introduction}

Neural circuits involving the basal ganglia have been implicated in motor control and learning, and their dysfunction causes movement disorders such as Parkinson's disease, Huntington's disease (HD), and hemiballism (DeLong, 1990; Obeso et al., 2000; Sieradzan and Mann, 2001). The striatum and subthalamic nucleus (STN) are the input stations of the basal ganglia and receive excitatory afferents from the cerebral cortex. The majority of striatal neurons are GABAergic medium spiny projection neurons (MSNs), whereas the STN is composed of excitatory glutamatergic neurons. The current model of the basal ganglia circuitry is that three parallel pathways connect the input stations and output nuclei of the basal ganglia, the substantia nigra pars reticulata (SNr) and entopeduncular nucleus (EPN) (Albin et al.,

\footnotetext{
Received Oct. 22, 2012; revised Feb. 27, 2013; accepted March 20, 2013.

Author contributions: H.S., S.C., T.H., K.K., and A.N. designed research; H.S. performed research; H.S. and S.C. analyzed data; H.S. and A.N. wrote the paper.

This research was supported by the Ministry of Education, Culture, Sports, Science and Technology (MEXT) of Japan (Grant-in-Aid for Young Scientists B \#20700353 and \#23700479 to H.S. and Grant-in-Aid for Scientific Research A \#21240039 to A.N.), The Japan Science Society (Sasakawa Scientific Research Grant to H.S.), the Takeda Science Foundation (to A.N.). A portion of this study is the result of the "Highly creative animal model development for brain sciences" performed under the Strategic Research Program for Brain Sciences by MEXT. We thank Shigeki Sato and Kana Miyamoto for technical assistance.

The authors declare no competing financial interests.

Correspondence should be addressed to Atsushi Nambu, Division of System Neurophysiology, National Institute for Physiological Sciences, 38 Nishigonaka, Myodaiji, 0kazaki, 444-8585, Japan. E-mail: nambu@nips.ac.jp.

DOI:10.1523/JNEUROSCI.4932-12.2013

Copyright $\odot 2013$ the authors $\quad 0270-6474 / 13 / 337583-12 \$ 15.00 / 0$
}

1989; Alexander and Crutcher, 1990; Gerfen, 1992; Mink and Thach, 1993; Hikosaka et al., 2000; Nambu et al., 2002). The first is the direct pathway, which arises from MSNs expressing substance $\mathrm{P}$ and dopamine $\mathrm{D} 1$ receptors (D1Rs) and projects directly to the $\mathrm{SNr} / \mathrm{EPN}$. The second is the indirect pathway, which arises from MSNs expressing enkephalin and dopamine D2 receptors (D2Rs) and projects indirectly to the $\mathrm{SNr} / \mathrm{EPN}$ through the sequential connections of the globus pallidus (GP) and STN. The third is the hyperdirect pathway, which conveys direct cortical inputs to the SNr/EPN through the STN. These three pathways exert different effects on SNr/EPN activity and the control of movements: the direct pathway decreases SNr/EPN activity and facilitates movements by disinhibiting thalamocortical activity, whereas the hyperdirect and indirect pathways increase the $\mathrm{SNr}$ / EPN activity and suppress movements by strengthening the inhibition of thalamocortical activity.

This model is supported by the motor impairments caused by striatal and STN dysfunction (including Parkinson's disease, HD, and hemiballism) (DeLong, 1990) and by studies showing that abnormal motor behaviors are induced by selective activation/ inactivation of the direct and indirect pathways (Kreitzer and Berke, 2011), such as D1R/D2R knock-out mice (Xu et al., 1994; Baik et al., 1995), deleting a target of intracellular signaling in D1R/D2R-expressing MSNs (Bateup et al., 2010), reversible inactivation of D1R/D2R-expressing MSNs using tetanus toxin (Hikida et al., 2010), and rapid activation of D1R/D2Rexpressing MSNs using optogenetics (Kravitz et al., 2010). Previ- 
ously, we selectively ablated D2R-expressing striatal neurons (i.e., striatopallidal MSNs and cholinergic interneurons; Sano et al., 2003) in mice using an immunotoxin (IT)-mediated cell targeting method (Kobayashi et al., 1995). Unilateral ablation of D2R-expressing striatal neurons induced contralateral rotations, and bilateral ablation induced motor hyperactivity and increased spontaneous locomotion. Based on these findings, it was considered that the loss of striatopallidal projections increased GP activity and decreased $\mathrm{SNr}$ activity through the GP-STN-SNr indirect pathway, thereby inducing motor hyperactivity. In the present study, we recorded neuronal activity in the GP and $\mathrm{SNr}$ before and after the ablation of D2R-expressing striatal neurons in awake mice. Contrary to the above expectations, little effects were observed on spontaneous activity in the GP and SNr. Instead, the response patterns of these neurons to cortical stimulation revealed dramatic changes, and these results require reconsideration of the static model of basal ganglia functions.

\section{Materials and Methods}

Animals. The experimental procedures were approved by the Institutional Animal Care and Use Committee of National Institutes of Natural Sciences. Five D2R heterozygous mutant mice (15-30 weeks old, male and female) and four age-matched wild-type littermates were used in the present study. In the D2R mutant mouse, human interleukin-2 receptor alpha $(\mathrm{IL}-2 \mathrm{R} \alpha)$ is expressed in D2R-expressing cells using a knock-in approach (Sano et al., 2003). D2R mutant mice were backcrossed to C57BL/6J mice for more than 10 generations. Seven MG-IG mutant mice (15-30 weeks old, male and female) were also used. In the MG-IG mutant mouse, human IL-2R $\alpha$ fused to the jellyfish green fluorescent protein is expressed under the control of the metabotropic glutamate receptor 2 (mGluR2) promoter and shows selective expression in striatal cholinergic interneurons (Kaneko et al., 2000; Hikida et al., 2001). Before the experiments, each mouse was trained daily to be habituated to handling by humans.

Surgery. To painlessly fix the head of the awake mouse to the stereotaxic apparatus, a small U-frame head holder was first mounted on the mouse's head as described previously (Chiken et al., 2008). Briefly, each mouse was anesthetized with ketamine hydrochloride $(100 \mathrm{mg} / \mathrm{kg}$ body weight, i.p.) and xylazine hydrochloride ( $5 \mathrm{mg} / \mathrm{kg}$ body weight, i.p.) and fixed in the stereotaxic apparatus. The skull was widely exposed and the periosteum and blood on the skull were completely removed. The exposed skull was completely covered with bone-adhesive resin (Bistite II; Tokuyama Dental) and acrylic resin (Unifast II; GC Corporation), and then a small polyacetal U-frame head holder for head fixation was mounted and fixed with acrylic resin on the head of the mouse.

After recovery from the first surgery ( 2 or $3 \mathrm{~d}$ later), the mouse was positioned in a stereotaxic apparatus with its head restrained using the U-frame head holder under light anesthesia with ketamine hydrochloride $(50-100 \mathrm{mg} / \mathrm{kg}$, i.p.). Part of the skull in one hemisphere was removed to access the motor cortex, striatum, GP, and SNr. A bipolar stimulating electrode made of 50- $\mu \mathrm{m}$-diameter Teflon-coated tungsten wires (intertip distance, $300-400 \mu \mathrm{m}$ ) was permanently implanted into the anterior part of the motor cortex. This part was identified as the orofacial region by intracortical microstimulation (train of 10 pulses at $333 \mathrm{~Hz}, 200 \mu$ s duration, up to $30 \mu \mathrm{A}$ ). The posterior part of the motor cortex was saved for vertical access to the striatum.

Recording of neural activity. After recovery from the second surgery, the awake mouse was positioned in a stereotaxic apparatus using the $\mathrm{U}$-frame head holder. For single-unit recording in the GP and SNr ipsilateral to the motor cortex with the stimulating electrode, a glass-coated Elgiloy microelectrode $(0.6-1.2 \mathrm{M} \Omega$ at $1 \mathrm{kHz})$ was inserted vertically into the brain through the dura mater using a hydraulic microdrive. The target area from the bregma was $\mathrm{P}$ (posterior) $0.1-0.7 \mathrm{~mm}$, L (lateral) $1.6-2.5 \mathrm{~mm}$ for the GP, and P 2.5-3.2 mm, L 1.5-2.0 mm for the $\mathrm{SNr}$ (Franklin and Paxinos, 2008). Unit activity of GP and SNr neurons recorded from the microelectrode was amplified and filtered (0.3-5.0 $\mathrm{kHz}$ ), converted to digital data with a window discriminator, and sam-

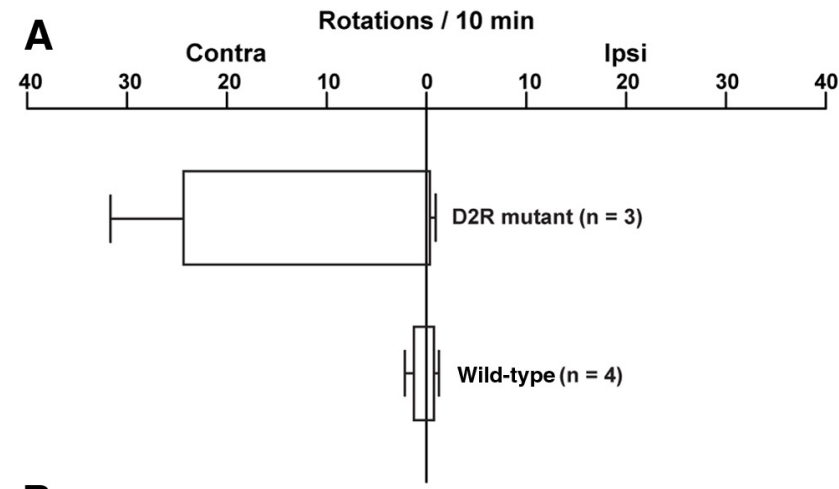

B
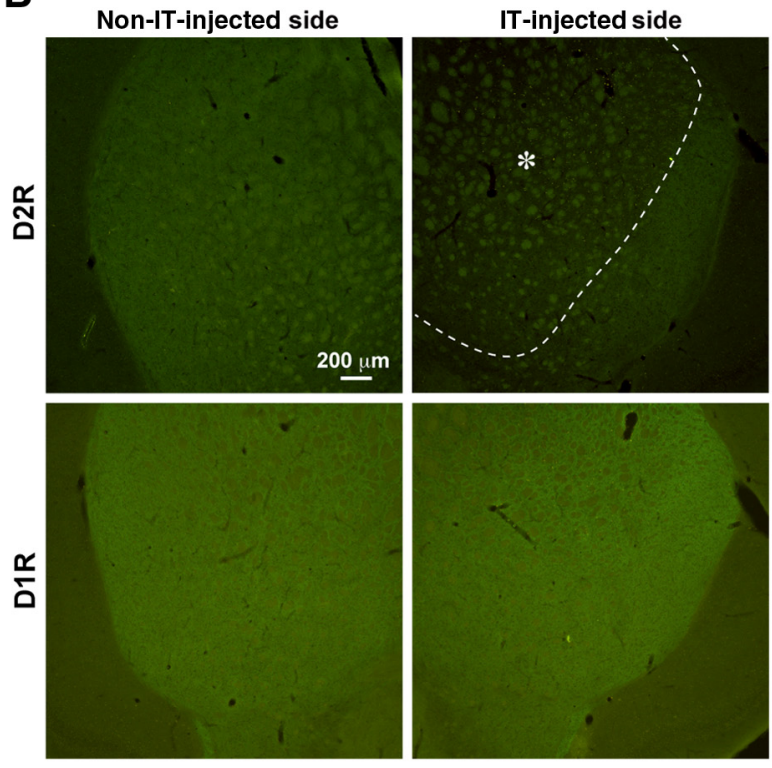

Figure 1. Rotational behavior and histology after IT treatment in D2R mutant mice, in which human IL-2R $\alpha$ is expressed in D2R-expressing cells. $\boldsymbol{A}$, After IT treatment into the striatum, the numbers of spontaneous rotations in the contralateral (Contra) and ipsilateral (Ipsi) directions to the IT-injected side were counted for 10 min in D2R mutant and wild-type mice. Error bars represent SD. The number of mice used is indicated by $n$. $B$, The expression of D2Rs and D1Rs in the striatum was visualized in two frontal sections of a D2R mutant mouse with immunohistochemistry (fluorescently labeled with Alexa Fluor 488). Left, Non-IT-injected side; right, ITinjected side. Ablated area of D2R-expressing neurons is marked by an asterisk $\left({ }^{*}\right)$ and encircled by broken lines.

pled at $2.0 \mathrm{kHz}$ using a computer for online data analysis. Spontaneous discharges and the responses to cortical electrical stimulation $(200 \mu \mathrm{s}$ duration monophasic single pulse at $0.7 \mathrm{~Hz}, 20-50 \mu \mathrm{A}$ strength) through the electrode implanted in the motor cortex were recorded.

IT treatment into the striatum. After recording GP and SNr activity, IT solution was injected into the striatum. IT, anti-Tac $(\mathrm{Fv})-\mathrm{PE} 40$ was diluted $(10 \mu \mathrm{g} / \mathrm{ml})$ with $0.01 \mathrm{M}$ PBS containing $0.5 \mathrm{mg} / \mathrm{ml}$ mouse serum albumin (Sigma-Aldrich). A glass micropipette with a $30-\mu \mathrm{m}-$ diameter Teflon-coated tungsten wire inside for recording was connected to a Hamilton microsyringe. The glass micropipette was inserted into three sites in the striatum [A (anterior) $0.7 \mathrm{~mm}, \mathrm{~L} 2.0$ $\mathrm{mm}, \mathrm{V}$ (ventral) $3.0 \mathrm{~mm}$; A $0.2 \mathrm{~mm}, \mathrm{~L} 2.5 \mathrm{~mm}, \mathrm{~V} 3.0 \mathrm{~mm}$; P $0.3 \mathrm{~mm}$, L $2.7 \mathrm{~mm}, \mathrm{~V} 3.0 \mathrm{~mm}$ from bregma] ipsilateral to the recorded GP and $\mathrm{SNr}$. These sites were confirmed to be the sensorimotor zone of the striatum by the orthodromic responses to the motor cortical stimulation. IT solution was then injected $(0.5 \mu \mathrm{l}$ in each site, at $0.1 \mu \mathrm{l} / \mathrm{min})$ with a microinfusion pump (Micro4; WPI).

Behavioral analysis and recording of neural activity after IT treatment. After IT treatment, general behaviors were observed daily. Mice were placed in a spherical bowl $(25 \mathrm{~cm}$ diameter $) 7 \mathrm{~d}$ after IT treatment to monitor turning behavior, which was recorded with a digital 
A GP

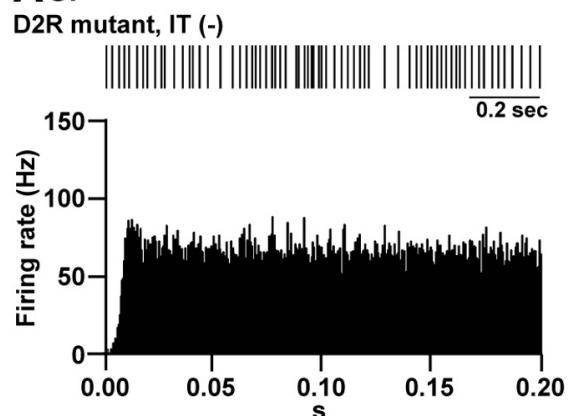

Wild-type, IT (-)
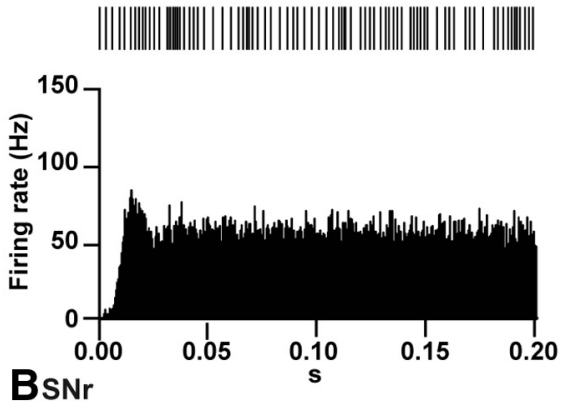

D2R mutant, IT (-)

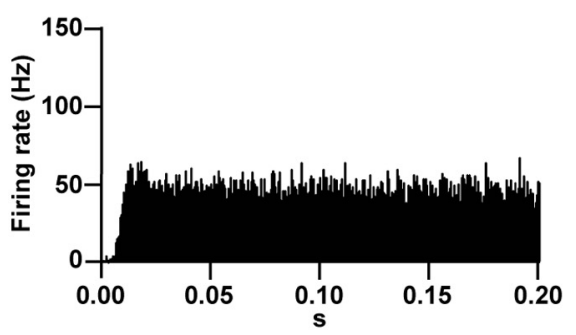

Wild-type, IT (-)

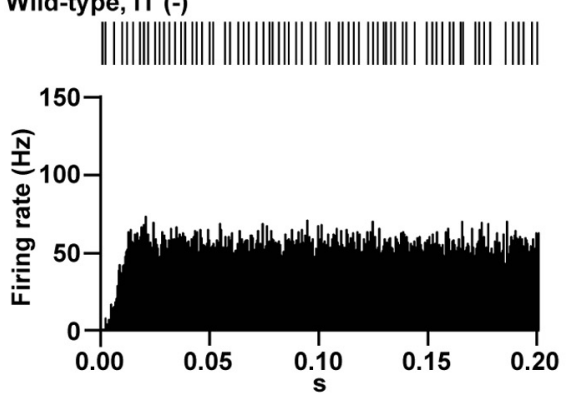

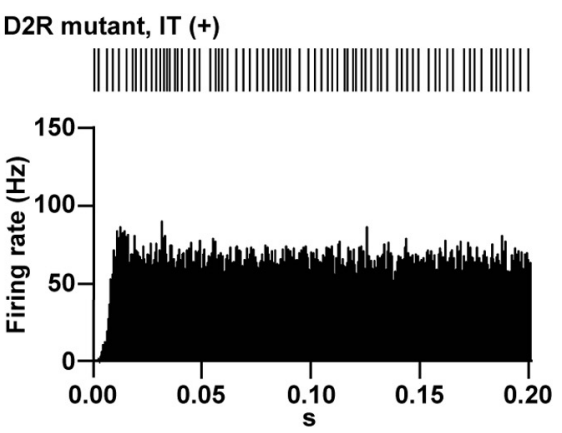

Wild-type, IT (+)
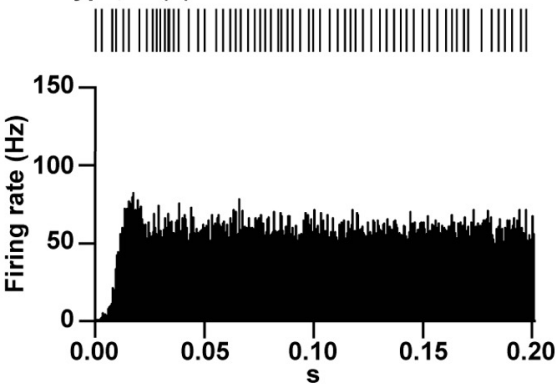

D2R mutant, IT (+)
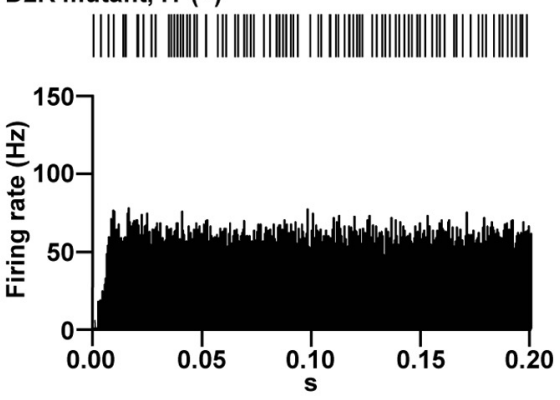

Wild-type, IT (+)

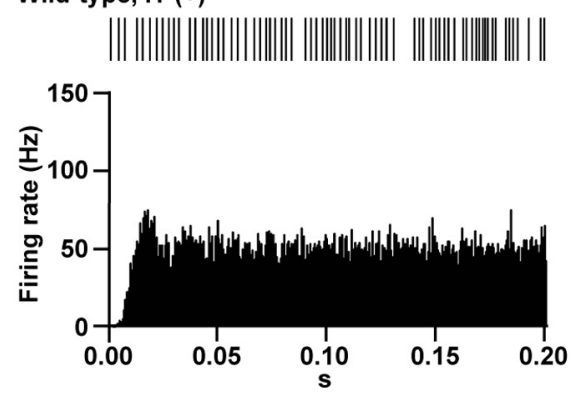

ISI) (Hutchison et al., 1998); the percentage of spikes in bursts detected by the Poisson surprise method (Poisson surprise value $\geq 2.0$, the minimum number of spikes during bursts was 3; Legéndy and Salcman, 1985; Chiken et al., 2008). In addition, the spontaneous firing pattern was analyzed by constructing autocorrelograms (bin width of $0.5 \mathrm{~ms}$ ) from continuous digitized recordings for $50 \mathrm{~s}$.

The neuronal responses to cortical electrical stimulation were assessed by constructing peristimulus time histograms (PSTHs; bin width of $1 \mathrm{~ms}$ ) for 100 stimulation trials. The mean value and SD of the firing rate during the 100 ms preceding the onset of stimulation were calculated from a PSTH and were considered the baseline discharge rate. Changes in the firing activity in response to cortical stimulation (i.e., excitation and inhibition) were judged to be significant if the firing rate during at least 2 consecutive bins $(2 \mathrm{~ms})$ reached the statistical level of $p<0.05$ (one-tailed $t$ test; Chiken et al., 2008; Tachibana et al., 2008). The latency of each response was defined as the time of the first bin exceeding this level. The responses were judged to end when two consecutive bins fell below the significance level. The end point was determined as the time of the last bin exceeding this level. The amplitude of each response was defined as the number of spikes during significant changes minus the number of spikes of the baseline discharge in the 100trials PSTH (i.e., the area of the response; positive and negative values indicate excitatory and inhibitory responses, respectively). For population PSTHs, the PSTH of each neuron with significant response to motor cortical stimulation was smoothed with a Gaussian window $(\sigma=2 \mathrm{~ms})$ and averaged separately for treatment (before and after the IT injection).

Histology. After the final recording, several sites of neuronal recording were marked by passing cathodal DC current (20 $\mu$ A for $20 \mathrm{~s}$ ) through the recording electrode. The mice were then deeply anesthetized with sodium pentobarbital (100 mg/kg, i.p.) and perfused transcardially with $0.01 \mathrm{M}$ PBS followed by $10 \%$ formalin in $0.01 \mathrm{~m}$ PBS. The brains were removed, postfixed in $10 \%$ formalin at $4^{\circ} \mathrm{C}$ overnight, and cryoprotected in $10 \%$ sucrose in $0.01 \mathrm{M} \mathrm{PBS}$ at $4^{\circ} \mathrm{C}$ overnight and then in $30 \%$ sucrose in $0.01 \mathrm{M} \mathrm{PBS}$ at $4^{\circ} \mathrm{C}$. Frontal sections $(40 \mu \mathrm{m})$ were cut with a freezing microtome and collected in $0.01 \mathrm{~m}$ PBS.

Several of the brain sections were mounted on MAS-coated slides (Matsunami Glass), air dried, and stained with Neutral Red. The re-

video camera. The number of rotations was counted for $10 \mathrm{~min}$. Recording of neuronal activity in the GP and SNr began at least $7 \mathrm{~d}$ after IT treatment. The same procedures as those before IT treatment were used.

Data analysis. The spontaneous firing rates and patterns, and the neuronal responses to cortical electrical stimulation of GP and SNr neurons of mutant and wild-type mice were monitored before and after IT treatment into the striatum.

The spontaneous firing rate was calculated from continuous digitized recordings for $50 \mathrm{~s}$. For firing pattern analyses, the following parameters were calculated from the same recordings: the mean, coefficient of variation (CV), kurtosis (3.0 in normal distribution), and skewness of interspike intervals (ISIs); the burst index (a ratio of the mean ISI to the mode cording sites were reconstructed according to the lesions made by the cathodal DC current and the traces of the electrode tracks. The remaining sections were used for immunohistochemistry to evaluate cell ablation by IT. Sections were treated according to standard histochemistry protocols as described previously (Sano et al., 2003). Free-floating sections were incubated with primary antibodies against human IL-2R $\alpha$ (1:1000; Sigma-Aldrich), mouse D1R (1:200; Frontier Institute), mouse D2R (1: 200, Frontier Institute), or goat choline acetyltransferase (1:200, EMD Millipore) at $4^{\circ} \mathrm{C}$ overnight, then visualized with secondary antibodies (1:1000) fluorescently labeled by Alexa Fluor 488 (Invitrogen) or with biotinylated secondary antibodies (1:1000; Vector Laboratories) and the ABC method (Vectastain Elite ABC Kit; Vector Laboratories). 
Table 1. Firing rates and patterns of GP and SNr neurons before $[\mathrm{IT}(-)]$ and after $[\mathrm{IT}(+)]$ IT treatment in D2R mutant and wild-type mice

\begin{tabular}{|c|c|c|c|c|}
\hline & \multicolumn{2}{|l|}{ D2R mutant } & \multicolumn{2}{|l|}{ Wild-type } \\
\hline & $\mathrm{IT}(-)$ & $\mathrm{IT}(+)$ & $\mathrm{IT}(-)$ & $\mathrm{IT}(+)$ \\
\hline \multicolumn{5}{|l|}{ GP } \\
\hline No. of neurons & 175 & 185 & 180 & 229 \\
\hline Firing rate $(\mathrm{Hz})$ & $62.55 \pm 19.78$ & $62.07 \pm 16.09$ & $59.71 \pm 14.42$ & $62.24 \pm 14.19$ \\
\hline \multicolumn{5}{|l|}{$\mathrm{ISI}$ (ms) } \\
\hline Mean & $17.65 \pm 6.36$ & $17.13 \pm 4.46$ & $17.57 \pm 3.72$ & $16.94 \pm 3.79$ \\
\hline CV & $0.75 \pm 0.19$ & $0.66 \pm 0.19^{*}$ & $0.73 \pm 0.20$ & $0.61 \pm 0.18^{*}$ \\
\hline Kurtosis & $15.12 \pm 12.66$ & $10.03 \pm 15.96^{*}$ & $14.41 \pm 14.46$ & $12.83 \pm 23.74^{*}$ \\
\hline Skewness & $3.25 \pm 1.95$ & $2.32 \pm 1.53^{*}$ & $3.09 \pm 2.20$ & $2.46 \pm 2.74^{*}$ \\
\hline Burst index & $1.13 \pm 0.34$ & $1.18 \pm 0.31$ & $1.12 \pm 0.20$ & $1.13 \pm 0.25$ \\
\hline Spikes in & $2.18 \pm 3.38$ & $1.74 \pm 2.74$ & $1.95 \pm 3.22$ & $2.05 \pm 2.48$ \\
\hline \multirow{2}{*}{\multicolumn{5}{|c|}{ burst (\%) }} \\
\hline & & & & \\
\hline No. of neurons & 97 & 101 & 122 & 167 \\
\hline Firing rate $(\mathrm{Hz})$ & $52.83 \pm 12.86$ & $55.88 \pm 15.45$ & $52.03 \pm 14.93$ & $54.25 \pm 13.56$ \\
\hline \multicolumn{5}{|l|}{ ISI (ms) } \\
\hline Mean & $20.37 \pm 4.97$ & $19.35 \pm 5.69$ & $20.79 \pm 5.50$ & $19.51 \pm 4.69$ \\
\hline CV & $0.72 \pm 0.17$ & $0.63 \pm 0.19^{*}$ & $0.69 \pm 0.19$ & $0.61 \pm 0.20^{*}$ \\
\hline Kurtosis & $7.89 \pm 6.92$ & $10.83 \pm 16.24$ & $9.78 \pm 6.05$ & $12.81 \pm 18.21$ \\
\hline Skewness & $2.00 \pm 0.42$ & $2.10 \pm 1.00$ & $1.97 \pm 0.62$ & $2.35 \pm 1.74$ \\
\hline Burst index & $1.14 \pm 0.23$ & $1.05 \pm 0.33^{*}$ & $1.20 \pm 0.34$ & $1.08 \pm 0.26^{*}$ \\
\hline Spikes in & $3.33 \pm 3.48$ & $2.95 \pm 5.04$ & $2.89 \pm 3.95$ & $2.46 \pm 2.37$ \\
\hline burst (\%) & & & & \\
\hline
\end{tabular}

Values are mean $\pm S D$.

${ }^{*} p<0.01$, significantly different from IT $(-)$ by repeated-measures ANOVA.

\section{Results}

\section{Spontaneous activity of GP and $\mathrm{SNr}$ neurons}

We recorded spontaneous activity of $175 \mathrm{GP}$ and $97 \mathrm{SNr}$ neurons from five awake D2R mutant mice before IT treatment into the striatum. These mice express human IL-2R $\alpha$ in D2R-expressing cells, and IT was injected into the striatum to induce selective ablation of D2R-expressing striatal neurons (see Materials and Methods). After IT treatment, one mutant mouse died. We observed behavioral changes in the remaining four mice: three D2R mutant mice showed contralateral rotations to the IT-injected side $7 \mathrm{~d}$ after IT treatment (Fig. 1A), which is consistent with our previous study (Sano et al., 2003). We then recorded spontaneous activity of $185 \mathrm{GP}$ and $101 \mathrm{SNr}$ neurons from these three mice after IT treatment into the striatum. After recording, we confirmed histologically that human IL-2R $\alpha$-expressing (data not shown) and D2R-expressing neurons were selectively ablated in the striatum of D2R mutant mice (Fig. $1 B$, top, ablated area marked by an asterisk and encircled by broken lines) without affecting D1R-expressing neurons (Fig. $1 B$, bottom), which is also consistent with our previous study (Sano et al., 2003). We also recorded spontaneous activity of GP and $\mathrm{SNr}$ neurons in wild-type mice before (180 GP and $122 \mathrm{SNr}$ neurons from four mice) and after (229 GP and 167 SNr neurons from the same four mice) IT treatment for comparison. These wild-type mice did not show rotational behavior after IT treatment (Fig. 1A; Sano et al., 2003).

The firing rates and patterns of GP neurons were compared in D2R mutant and wild-type mice before and after IT treatment (Fig. 2A, Table 1). We observed no statistical difference in the firing rates between the two genotypes before and after IT treatment (repeated-measures ANOVA: interaction, $p=0.20$; genotype, $p=0.25$; treatment, $p=0.38$ ). GP neurons in both genotypes fired continuously and irregularly before and after IT treatment, as shown in the trace of digitized spikes and autocorrelograms (Fig. 2A). We observed no apparent difference in the firing pattern between the two genotypes before and after IT treatment (Table 1). There was no statistical difference in the mean of ISIs, burst index, or percentage of spikes in burst (repeated-measures ANOVA: mean of ISIs: interaction, $p=0.87$; genotype, $p=0.69$; treatment, $p=0.09$; burst index: interaction, $p=0.32$; genotype, $p=0.14$; treatment, $p=0.14$; percentage of spikes in burst: interaction, $p=0.20$; genotype, $p=0.85$; treatment, $p=0.42$ ). The CV, kurtosis, and skewness of ISIs decreased slightly after IT treatment in both genotypes (repeated-measures ANOVA: CV of ISIs: interaction, $p=0.27$; genotype, $p=0.02$; treatment, $p<0.0001$; kurtosis of ISIs: interaction, $p=0.17$; genotype, $p=0.42$; treatment, $p=0.009$; skewness of ISIs: interaction, $p=0.34$; genotype, $p=0.95$; treatment, $p<0.0001$ ).

Activity of SNr neurons was also compared in D2R mutant and wild-type mice before and after IT treatment (Fig. 2B, Table 1). $\mathrm{SNr}$ neurons showed behaviors similar to those of GP neurons. We observed no statistical difference in the firing rates of SNr neurons between the two genotypes before and after IT treatment (repeated-measures ANOVA: interaction, $p=0.75$; genotype, $p=0.36$; treatment, $p=0.06$ ). We observed no apparent difference in the firing pattern of $\mathrm{SNr}$ neurons between the two genotypes before and after IT treatment (Fig. 2B, Table 1). We observed no statistical difference in the mean, kurtosis, or skewness of ISIs or the percentage of spikes in burst (repeatedmeasures ANOVA: mean of ISIs: interaction, $p=0.06$; genotype, $p=0.34$; treatment, $p=0.34$; kurtosis of ISIs: interaction, $p=$ 0.97 ; genotype, $p=0.13$; treatment, $p=0.02$; skewness of ISIs: interaction, $p=0.20$; genotype, $p=0.31$; treatment, $p=0.03$; percentage of spikes in burst: interaction, $p=0.94$; genotype, $p=$ 0.17 ; treatment, $p=0.24$; Table 1 ). The CV of ISIs and burst index slightly decreased (repeated-measures ANOVA: CV of ISIs: interaction, $p=0.78$; genotype, $p=0.16$; treatment, $p<0.0001$; burst index: interaction, $p=0.58$; genotype, $p=0.10$; treatment, $p=0.0001$; Table 1) after IT treatment in both genotypes.

\section{Responses of GP neurons to cortical stimulation}

We then recorded the activity of GP and SNr neurons induced by motor cortical stimulation before and after IT treatment in D2R mutant and wild-type mice by constructing PSTHs. To understand the mechanism underlying motor hyperactivity, it is essential to understand how neuronal signals that originate in the motor cortex are transmitted through the basal ganglia. Cortical stimulation can mimic cortical activity during voluntary movements (Kita et al., 2004; Tachibana et al., 2008) and cortically induced responses in the basal ganglia are altered in hyperkinetic and hypokinetic movement disorders (Chiken et al., 2008; Kita and Kita, 2011; Nishibayashi et al., 2011).

Before IT treatment, stimulation of the motor cortex induced responses in 64 of 175 (37\%) GP neurons recorded in D2R mutant mice and in 59 of 180 (33\%) GP neurons recorded in wildtype mice. The typical response pattern of GP neurons evoked by motor cortical stimulation is a triphasic response consisting of early excitation, inhibition, and late excitation (Chiken et al., 2008), and this pattern was seen in both genotypes (Fig. 3A, left). Although the major response pattern was a triphasic response, other response patterns, such as excitation followed by inhibition, inhibition followed by excitation, and monophasic or biphasic excitation, were also observed (Fig. $3 B$ ). The populations of these response patterns were similar between the two genotypes.

After IT treatment, stimulation of the motor cortex induced responses in 97 of 185 (52\%) GP neurons in D2R mutant mice 


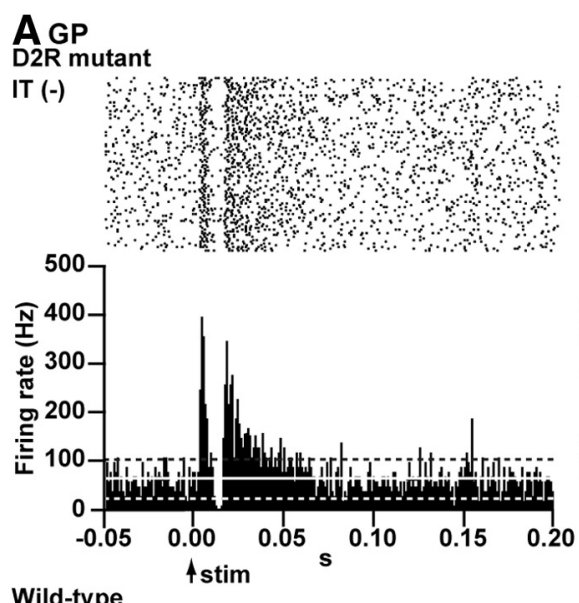

Wild-type
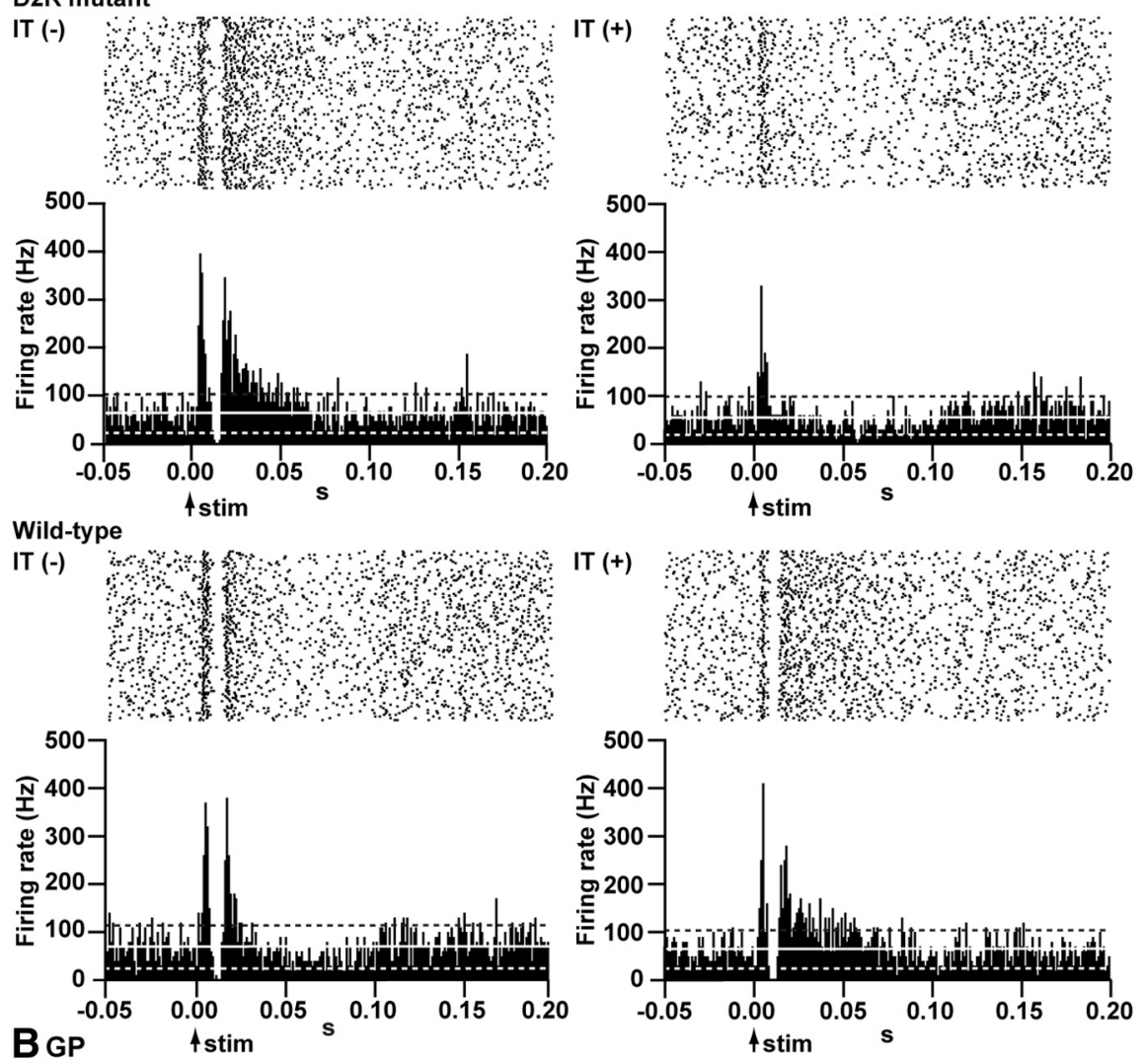

IT (+)
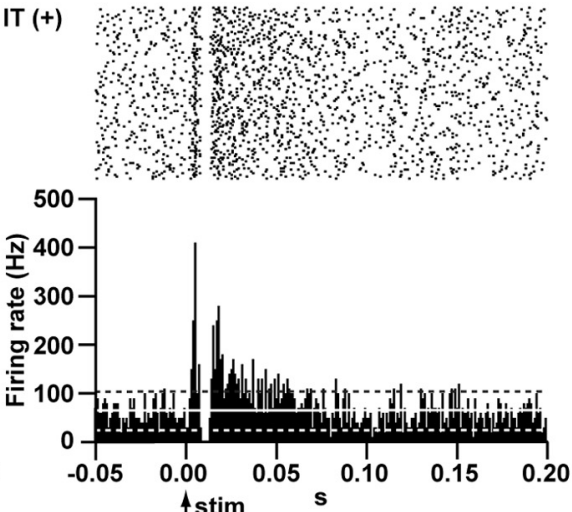

$\%$ of neurons

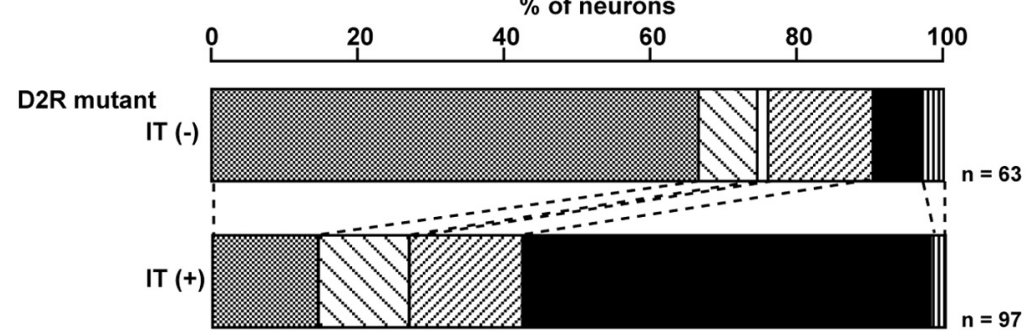

Wild-type

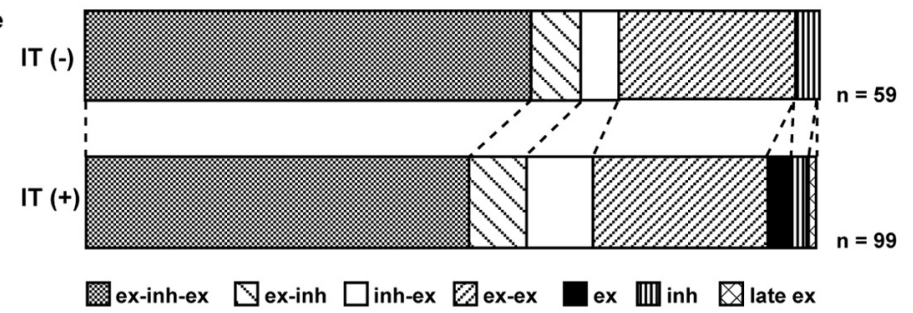

Figure 3. Response pattern changes of GP neurons to motor cortical stimulation after the ablation of D2R-expressing neurons. $\boldsymbol{A}$, Raster and PSTHs of the typical response of GP neurons to motor cortical stimulation before [IT( -$)]$ and after [IT(+)] IT treatment into the striatum of D2R mutant and wild-type mice. Cortical stimulation ( $200 \mu$ s duration single pulse, $50 \mu A$ strength) was delivered at time 0 (arrows) for 100 stimulus trials. The mean firing frequency and statistical levels of $p<0.05$ (one-tailed $t$ test) calculated from the $100 \mathrm{~ms}$ period preceding the onset of stimulation are indicated by solid white lines (mean) and dotted lines (statistical levels), respectively. $\boldsymbol{B}$, Proportions of GP neurons classified according to the response patterns evoked by motor cortical stimulation before $[I T(-)]$ and after $[I T(+)] I T$ treatment into the striatum of D2R mutant and wild-type mice. ex indicates excitation; inh, inhibition.

and in 99 of 229 (43\%) GP neurons in wild-type mice. The typical response pattern in $\mathrm{D} 2 \mathrm{R}$ mutant mice was monophasic early excitation (Fig. $3 A$, top right). The number of GP neurons showing a triphasic response pattern was significantly decreased, and the number showing a monophasic early excitation pattern was significantly increased after IT treatment $\left(\chi^{2}\right.$ test, $p<0.0001$; Fig.
$3 B)$. Other response patterns, such as excitation followed by inhibition and biphasic excitation, were also observed, and the population of these response patterns was not changed after IT treatment in D2R mutant mice (Fig. 3B). Conversely, the typical response pattern in wild-type mice remained a triphasic response after IT treatment (Fig. $3 A$, bottom, $B$ ).

These changes in GP neurons of D2R mutant mice were also evident in population PSTHs $[\operatorname{IT}(-): n=64$; IT $(+): n=97$; Fig. $4 A]$. The amplitudes of the inhibition and late excitation were largely reduced after IT treatment, whereas the amplitude of the early excitation remained unchanged. These changes were further examined quantitatively by analyzing the latency, duration, and amplitude of each component (Table 2). Not only did the number of GP neurons with inhibition and/or late excitation decrease, but the amplitudes of inhibition and late excitation were also significantly reduced after IT treatment [repeatedmeasures ANOVA: inhibition: interaction, $p=0.0002$; genotype, $p=0.023$; treatment, $p<0.0001$; Tukey's post hoc test, D2R mutant IT $(-)$ vs D2R mutant IT $(+), p<0.05$; wild-type IT $(-)$ vs D2R mutant IT $(+), p<$ 0.05 ; wild-type $\mathrm{IT}(+)$ vs $\mathrm{D} 2 \mathrm{R}$ mutant IT $(+), p<0.05$; late excitation: interaction, $p=0.0003$; genotype, $p<0.0001$; treatment, $p<0.0001$; Tukey's post hoc test, D2R mutant IT $(-)$ vs D2R mutant IT $(+), p<$ 0.05 ; wild-type $\mathrm{IT}(-)$ vs $\mathrm{D} 2 \mathrm{R}$ mutant IT( + ), $p<0.05$; wild-type IT(+) vs D2R mutant IT $(+), p<0.05]$. Conversely, the latency, duration, and amplitude of the early excitation remained unchanged in D2R mutant mice after IT treatment. These parameters showed few changes after IT treatment in wild-type mice.

\section{Responses of SNr neurons to cortical stimulation}

Before IT treatment, stimulation of the motor cortex induced responses in 76 of 97 (78\%) SNr neurons recorded in D2R mutant mice and in 58 of $122(48 \%) \mathrm{SNr}$ neurons recorded in wild-type mice. The typical response pattern of $\mathrm{SNr}$ neurons evoked by motor cortical stimulation was a triphasic response consisting of early excitation, inhibition, and late excitation, and this pattern was seen in both genotypes (Fig. 5A, left). Other response patterns, such as excitation followed by inhibition, inhibition followed by excitation, monophasic or biphasic excitation, and monophasic inhibition, were also observed in both genotypes (Fig. 5B).

After IT treatment, stimulation of the motor cortex induced responses in 44 of 101 (44\%) SNr neurons in D2R mutant mice and in 75 of 167 (45\%) SNr neurons in wild-type mice. The 
typical response pattern in D2R mutant mice was a biphasic response consisting of early excitation and inhibition (Fig. $5 A$, top right). The number of SNr neurons showing a triphasic response pattern was significantly decreased and the number showing a biphasic response composed of early excitation and inhibition was significantly increased after IT treatment $\left(\chi^{2}\right.$ test, $p=0.0004$, Fig. $5 B$ ). Other response patterns, such as inhibition followed by excitation, biphasic or monophasic excitation, and monophasic inhibition, were also observed (Fig. 5B). Conversely, the typical response pattern in wild-type mice remained triphasic after IT treatment (Fig. $5 A$, bottom right, $B$ ).

These changes in SNr neurons of D2R mutant mice were also evident in population PSTHs $[\operatorname{IT}(-): n=76$; $\operatorname{IT}(+): n=$ 44; Fig. $4 B$ ]. The amplitude of the late excitation was largely reduced, and that of the inhibition was increased after IT treatment, whereas the amplitude of the early excitation remained unchanged. These changes were further examined quantitatively by analyzing the latency, duration, and amplitude of each component (Table 2). In D2R mutant mice, the amplitudes of early excitation and late excitation tended to decrease after IT treatment, whereas the amplitude of inhibition tended to increase.

\section{Ablation of cholinergic interneurons}

D2Rs are expressed in both striatopallidal MSNs and cholinergic interneurons of the striatum (Yung et al., 1995). We showed
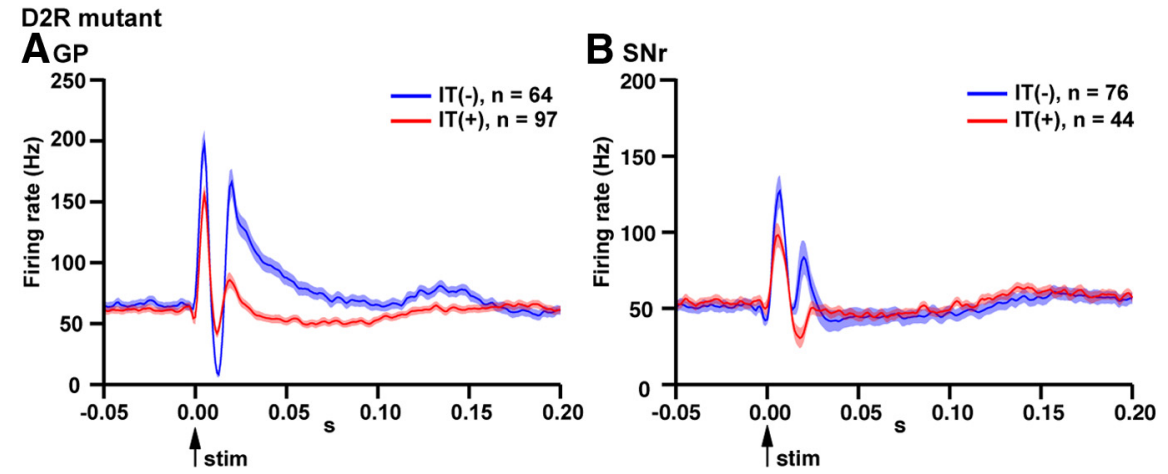

Figure 4. Changes in the population PSTHs of GP and SNr neurons after the ablation of D2R-expressing neurons. Population PSTHs of GP $(\boldsymbol{A})$ and $\mathrm{SNr}(\boldsymbol{B})$ neurons in D2R mutant mice before [IT( -$)$, blue lines] and after [IT(+), red lines] IT treatment into the striatum. The light-shaded colors represent \pm SEM. The number of neurons used is indicated by $n$.

Table 2. Response parameters of GP and SNr neurons to motor cortical stimulation before $[\mathrm{IT}(-)]$ and after $[\mathrm{IT}(+)] \mathrm{IT}$ treatment in D2R mutant and wild-type mice

\begin{tabular}{|c|c|c|c|c|}
\hline & \multicolumn{2}{|l|}{ D2R mutant } & \multicolumn{2}{|l|}{ Wild-type } \\
\hline & $\mathrm{IT}(-)$ & $\mathrm{IT}(+)$ & $\mathrm{IT}(-)$ & $\mathrm{IT}(+)$ \\
\hline \multicolumn{5}{|l|}{ GP } \\
\hline No. of neurons & 64 & 97 & 59 & 99 \\
\hline Early excitation & $n=61$ & $n=95$ & $n=54$ & $n=87$ \\
\hline Latency (ms) & $3.18 \pm 0.99$ & $3.67 \pm 1.45$ & $3.44 \pm 1.73$ & $3.29 \pm 1.42$ \\
\hline Duration (ms) & $5.00 \pm 1.61$ & $4.37 \pm 1.99$ & $5.57 \pm 2.77$ & $5.85 \pm 4.73$ \\
\hline Amplitude (spikes) & $71.37 \pm 33.13$ & $49.01 \pm 28.42$ & $66.98 \pm 49.02$ & $60.75 \pm 49.89$ \\
\hline Inhibition & $n=50$ & $n=28$ & $n=45$ & $n=71$ \\
\hline Latency (ms) & $9.98 \pm 1.61$ & $10.11 \pm 1.55$ & $10.33 \pm 2.55$ & $10.56 \pm 3.04$ \\
\hline Duration (ms) & $6.82 \pm 1.95$ & $5.82 \pm 2.91$ & $6.93 \pm 2.57$ & $5.97 \pm 3.23$ \\
\hline Amplitude (spikes) & $-32.39 \pm 23.65$ & $-9.63 \pm 17.04^{*, * *}$ & $-32.96 \pm 26.04$ & $-27.55 \pm 31.46$ \\
\hline Late excitation & $n=53$ & $n=29$ & $n=53$ & $n=86$ \\
\hline Latency (ms) & $17.21 \pm 1.45^{*}$ & $16.45 \pm 2.25^{*}$ & $18.49 \pm 2.06$ & $17.17 \pm 2.89$ \\
\hline Duration (ms) & $11.91 \pm 11.34^{*}$ & $6.90 \pm 5.44^{*}$ & $15.45 \pm 14.27$ & $16.26 \pm 12.42$ \\
\hline Amplitude (spikes) & $135.31 \pm 182.10$ & $17.83 \pm 42.37^{*, * *}$ & $163.58 \pm 186.10$ & $168.50 \pm 190.16$ \\
\hline \multicolumn{5}{|l|}{$\mathrm{SNr}$} \\
\hline No. of neurons & 76 & 44 & 58 & 75 \\
\hline Early excitation & $n=74$ & $n=33$ & $n=48$ & $n=59$ \\
\hline Latency (ms) & $6.38 \pm 2.79$ & $5.21 \pm 2.51$ & $5.00 \pm 2.73$ & $5.17 \pm 2.21$ \\
\hline Duration (ms) & $6.49 \pm 3.95$ & $5.09 \pm 2.81$ & $7.69 \pm 4.11$ & $6.17 \pm 3.77$ \\
\hline Amplitude (spikes) & $67.92 \pm 53.95^{*}$ & $29.76 \pm 27.18^{*}$ & $73.47 \pm 58.64$ & $60.64 \pm 59.36$ \\
\hline Inhibition & $n=51$ & $n=29$ & $n=46$ & $n=68$ \\
\hline Latency (ms) & $13.16 \pm 2.06$ & $14.21 \pm 2.44$ & $13.43 \pm 4.19$ & $14.31 \pm 5.68$ \\
\hline Duration (ms) & $6.27 \pm 3.16^{*}$ & $7.93 \pm 4.40^{*}$ & $10.80 \pm 7.43$ & $12.38 \pm 6.31$ \\
\hline Amplitude (spikes) & $-21.89 \pm 24.90^{*}$ & $-25.75 \pm 27.77^{*}$ & $-47.96 \pm 52.51$ & $-53.79 \pm 42.56$ \\
\hline Late excitation & $n=42$ & $n=13$ & $n=38$ & $n=46$ \\
\hline Latency (ms) & $20.33 \pm 2.86^{*}$ & $20.23 \pm 6.52^{*}$ & $25.08 \pm 7.01$ & $29.35 \pm 8.46$ \\
\hline Duration (ms) & $5.50 \pm 3.74^{*}$ & $5.08 \pm 3.12^{*}$ & $7.42 \pm 4.45$ & $7.20 \pm 4.59$ \\
\hline Amplitude (spikes) & $29.31 \pm 40.19^{*}$ & $12.36 \pm 27.50^{*}$ & $53.51 \pm 71.10$ & $42.23 \pm 61.66$ \\
\hline
\end{tabular}

Values are mean \pm SD. Neurons with significant early excitation, inhibition, and/or late excitation were used for calculation ( $n$ indicates number of neurons used). 

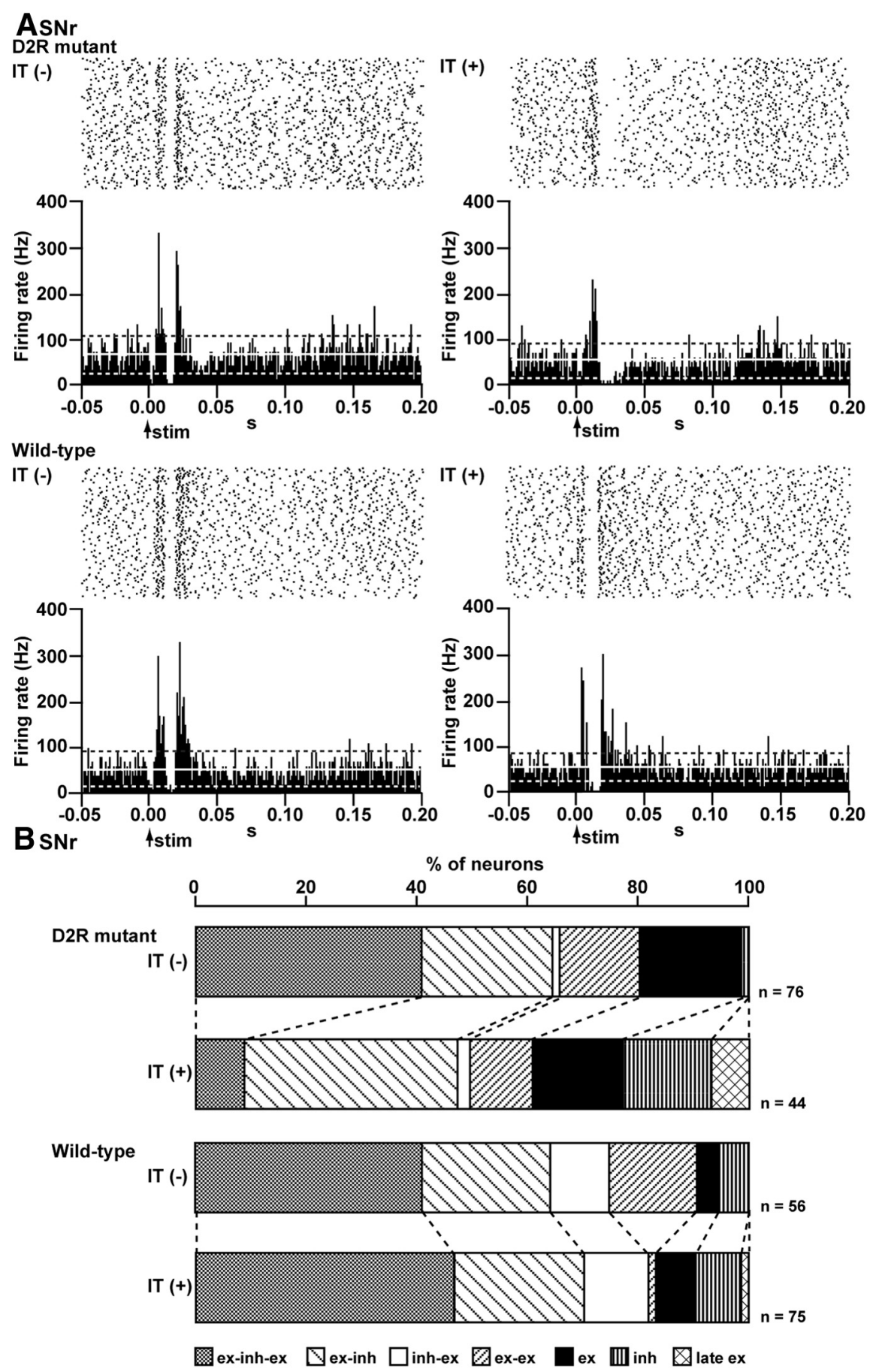

Figure 5. Response pattern changes of SNr neurons to motor cortical stimulation after the ablation of D2R-expressing neurons. A, Raster and PSTHs of the typical response of SNr neurons to motor cortical stimulation before [IT( -$)]$ and after $[\mathrm{IT}(+)]$ IT treatment into the striatum of D2R mutant and wild-type mice. B, Proportions of SNr neurons classified according to the response patterns evoked by motor cortical stimulation before and after IT treatment into the striatum of D2R mutant and wild-type mice.

which selectively express human IL-2R $\alpha$ (Kaneko et al., 2000; Hikida et al., 2001).

The activity of GP and SNr neurons in MG-IG mutant mice was recorded before (182 GP and $111 \mathrm{SNr}$ neurons from seven mice) and after (106 GP and $58 \mathrm{SNr}$ neurons from three of seven mice) IT treatment into the striatum. We confirmed histologically that striatal cholinergic neurons were selectively ablated after IT treatment (Fig. 6A, ablated area marked by an asterisk and encircled by broken lines). The firing rates, and the mean and CV of ISIs were compared before and after IT treatment (Table 3) and remained unchanged. GP and $\mathrm{SNr}$ neurons fired continuously and irregularly before and after IT treatment (Fig. 6B, C). We observed no obvious difference in the firing pattern before and after IT treatment.

In MG-IG mutant mice, 127 of 182 (70\%) GP and 55 of 111 (50\%) SNr neurons before IT treatment and 63 of 106 (59\%) GP and 22 of 58 (38\%) SNr neurons after IT treatment responded to stimulation of the motor cortex. The typical response pattern of GP and SNr neurons evoked by motor cortex stimulation was a triphasic response consisting of early excitation, inhibition, and late excitation; this pattern was major before IT treatment and remained unchanged after IT treatment (Fig. 7). The latencies, durations, and amplitudes in the early excitation, inhibition, and late excitation of GP and SNr neurons remained unchanged after IT treatment (Table 3). The observation that selective ablation of cholinergic interneurons had little effect on either spontaneous activity or cortically evoked responses in the GP and $\mathrm{SNr}$ suggests that the observed changes in cortically evoked responses in the GP and $\mathrm{SNr}$ of D2R mutant mice after IT treatment were derived primarily from the loss of striatopallidal MSNs expressing D2Rs, not from the loss of cholinergic interneurons expressing D2Rs.

\section{Location of recorded GP and SNr neurons}

The locations of recorded GP and SNr neurons in a D2R mutant mouse were plotted with different symbols according to the cortically evoked response patterns (Fig. 8). Before IT treatment, GP neurons responding to cortical stimulation were found in the ventrolateral part of the GP and the major response pattern was a triphasic response consisting of early excitation, inhibition, and late excitation (Fig. 8A, GP). After IT treatment, responsive neurons were found in the same area, but the major response pattern had changed to monophasic early excitation (Fig. 8B, GP). Similarly, SNr neurons responding to cortical stimulation were found in the lateral part of the $\mathrm{SNr}$ and the major response pattern was triphasic before IT treatment (Fig. $8 A, \mathrm{SNr}$ ). After IT treatment, responsive neurons were found in the same area, but the major response pattern was changed to a biphasic one consisting of early excitation and inhibition (Fig. $8 B, \mathrm{SNr}$ ). These observations indicate that activity of the same neuronal populations in the GP and SNr was recorded before and after IT treatment and that the response pattern itself changed after IT treatment. 


\section{Discussion}

The results of the present study reveal the following: (1) The ablation of D2Rexpressing neurons in the striatum had little effect on the spontaneous activity of GP and SNr neurons. (2) However, the ablation diminished cortically evoked inhibition in the GP and late excitation in the GP and SNr. (3) Theses changes derived primarily from the loss of striatopallidal MSNs, not by the loss of striatal cholinergic interneurons. (4) These animals showed contralateral rotations, so the reduction of phasic signals to suppress movements through the striatopallidal indirect pathway, rather than the changes in the spontaneous firing rates and patterns, seems to be responsible for motor hyperactivity and contralateral rotations in D2R mutant mice (Fig. 9).

Little effect on spontaneous activity of GP and $\mathrm{SNr}$ neurons

Based on the classical direct and indirect pathways model of the basal ganglia (Alexander and Crutcher, 1990), the striatopallidal projection is GABAergic and inhibits GP activity. The loss of striatopallidal neurons would be expected to disinhibit GP activity, which in turn would decrease $\mathrm{SNr}$ activity through the GPSTN-SNr indirect pathway, finally inducing motor hyperactivity. In fact, our previous study showed that the ablation of striatal D2R-expressing neurons increased both glutamic acid decarboxylase 67 mRNA level in the GP and spontaneous locomotion (Sano et al., 2003). Contrary to this model, the ablation of striatal D2R-expressing neurons produced no significant effects on the spontaneous fir-

\section{MG-IG mutant}

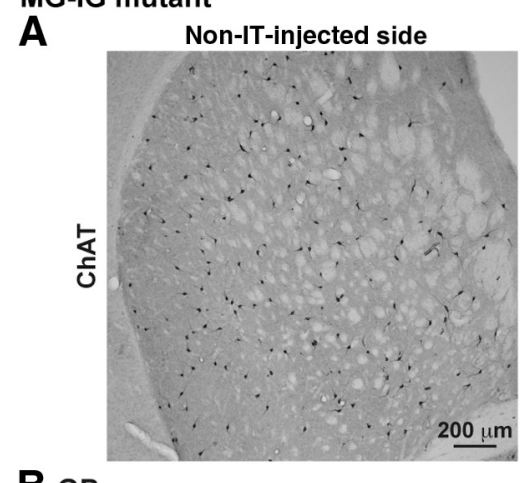

\section{B GP}

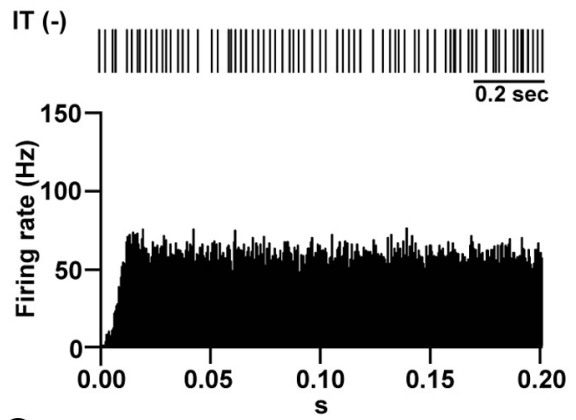

C sNr

IT (-)
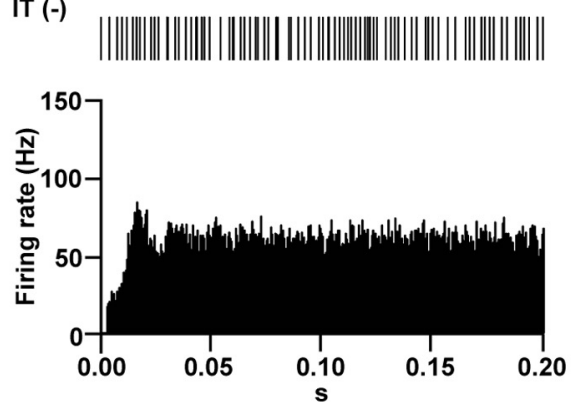

IT (+)
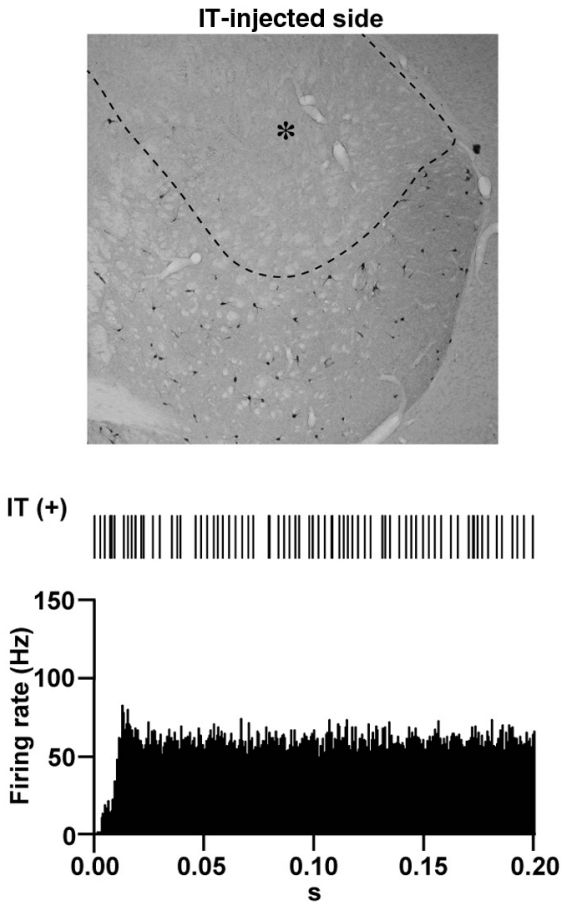

IT (+)
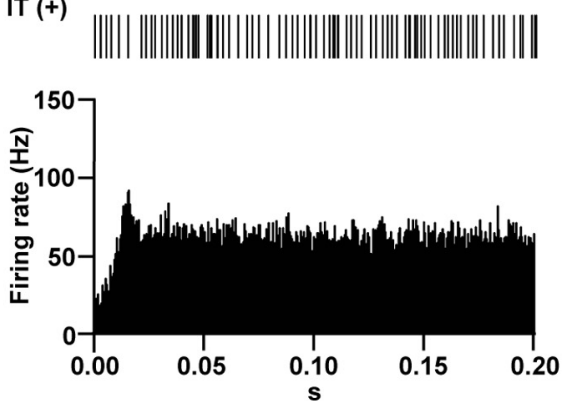

Figure 6. No apparent effects on spontaneous activity of GP and SNr neurons after the ablation of striatal cholinergic interneurons. $A$, The expression of choline acetyltransferase (ChAT) in the striatum was visualized with immunohistochemistry (ABC method) in MG-IG mutant mice in which human IL-2R $\alpha$ is selectively expressed in striatal cholinergic interneurons. Left, Non-ITinjected side; right, IT-injected side. Ablated area of cholinergic interneurons is marked by an asterisk $\left({ }^{*}\right)$ and encircled by broken lines. $\boldsymbol{B}, \boldsymbol{C}$, Slow traces of digitized spikes and autocorrelograms of spontaneous activity in the $\mathrm{GP}(\boldsymbol{B})$ and $\operatorname{SNr}(\boldsymbol{C})$ before $[\mathrm{IT}(-)]$ and after $[I T(+)]$ IT treatment into the striatum of MG-IG mutant mice.

Table 3. Firing rates and response parameters to motor cortical stimulation of GP and SNr neurons before [IT(-)] and after [IT(+)] IT treatment in MG-IG mutant mice

\begin{tabular}{|c|c|c|c|c|}
\hline & \multicolumn{2}{|l|}{ GP } & \multicolumn{2}{|l|}{$\mathrm{SNr}$} \\
\hline & $\mathrm{IT}(-)$ & $\mathrm{IT}(+)$ & $\mathrm{IT}(-)$ & $\mathrm{IT}(+)$ \\
\hline $\begin{array}{l}\text { No. of neurons } \\
\text { Firing rate (Hz) } \\
\text { Mean of ISI (ms) } \\
\text { CV of ISI }\end{array}$ & $\begin{array}{l}182 \\
60.96 \pm 15.05 \\
17.58 \pm 5.02 \\
0.66 \pm 0.18\end{array}$ & $\begin{array}{l}106 \\
63.80 \pm 11.98 \\
16.14 \pm 3.01 \\
0.62 \pm 0.15\end{array}$ & $\begin{array}{l}111 \\
57.07 \pm 16.24 \\
19.04 \pm 5.58 \\
0.66 \pm 0.20\end{array}$ & $\begin{array}{l}58 \\
60.12 \pm 14.34 \\
17.70 \pm 4.80 \\
0.61 \pm 0.15\end{array}$ \\
\hline No. of neurons & 127 & 63 & 55 & 22 \\
\hline Amplitude (spikes) & $65.88 \pm 43.38$ & $54.19 \pm 31.48$ & $104.83 \pm 77.61$ & $83.93 \pm 49.01$ \\
\hline Inhibition & $n=80$ & $n=38$ & $n=25$ & $n=13$ \\
\hline Latency (ms) & $10.29 \pm 3.02$ & $9.41 \pm 2.16$ & $13.50 \pm 6.05$ & $13.12 \pm 5.42$ \\
\hline Duration (ms) & $7.66 \pm 6.26$ & $7.00 \pm 2.94$ & $9.82 \pm 7.41$ & $8.84 \pm 4.36$ \\
\hline Amplitude (spikes) & $-43.36 \pm 43.37$ & $-44.8 \pm 24.6$ & $-50.69 \pm 42.01$ & $-38.9 \pm 22.12$ \\
\hline Late excitation & $n=92$ & $n=49$ & $n=32$ & $n=15$ \\
\hline
\end{tabular}

Values are mean \pm SD. Neurons with significant early excitation, inhibition, and/or late excitation were used for calculation ( $n$ indicates number of neurons used). 

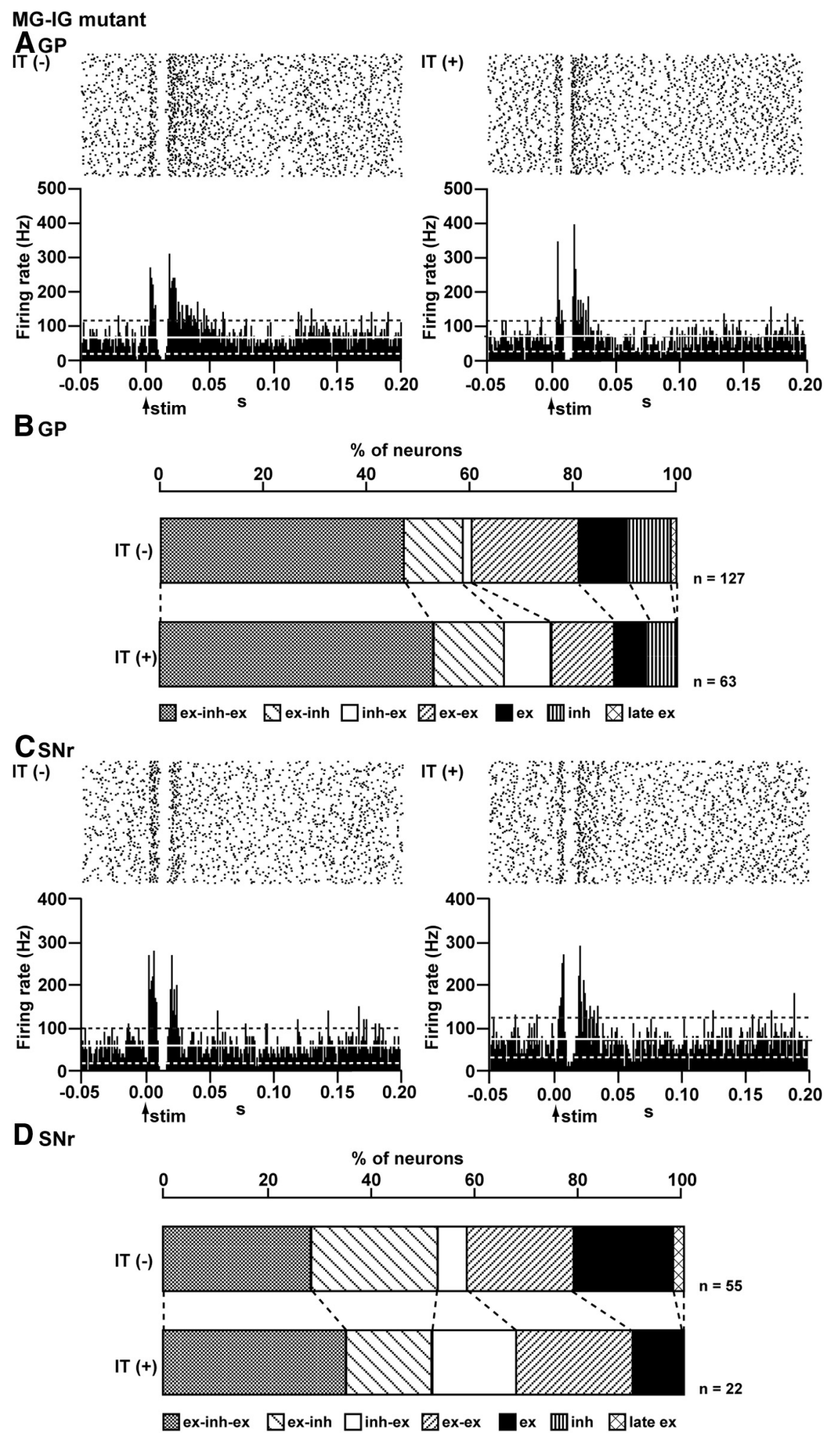

Figure 7. No apparent effects on the response patterns of GP and SNr neurons to motor cortical stimulation after the ablation of striatal cholinergic interneurons. $\boldsymbol{A}, \boldsymbol{C}$, Raster and PSTHs of the typical response of $\mathrm{GP}(\boldsymbol{A})$ and $\mathrm{SNr}(\boldsymbol{C})$ neurons to motor cortical stimulation before $[I T(-)]$ and after $[I T(+)]$ IT treatment into the striatum of MG-IG mutant mice. $\boldsymbol{B}, \boldsymbol{D}$, Proportions of GP $(\boldsymbol{B})$ and $\mathrm{SNr}(\boldsymbol{D})$ neurons classified according to the response patterns evoked by motor cortical stimulation before and after IT treatment into the striatum of MG-IG mutant mice.

ing rates and patterns of GP and $\mathrm{SNr}$ neurons in the present study (Fig. 2, Table 1). These data suggest that the striatopallidal MSNs and cholinergic interneurons have limited effect on spontaneous activity of GP and SNr neurons and that this model cannot ex- plain the mechanism of motor hyperactivity observed after the ablation of the striatopallidal projection.

\section{Changes of cortically evoked responses in $\mathrm{GP}$ and $\mathrm{SNr}$ neurons}

Motor cortical neurons are activated in a highly synchronized manner when voluntary movement is about to be initiated, and this cortical activity is transmitted to the basal ganglia (Nambu et al., 2002). Therefore, examining how the excitation in the motor cortex modulates the activity of the basal ganglia is crucial for understanding their functions. Previous electrophysiological studies showed that cortical stimulation evokes a triphasic response consisting of early excitation, inhibition, and late excitation in the GP, $\mathrm{SNr}$, and EPN of rodents (Ryan and Clark, 1991; Fujimoto and Kita, 1992; Kita, 1992; Maurice et al., 1999), and in the external and internal segments of the globus pallidus (GPe and GPi, corresponding to the GP and EPN, respectively) and $\mathrm{SNr}$ of monkeys (Yoshida et al., 1993; Kitano et al., 1998). The responsible pathways for each component have been intensively studied (Ryan and Clark, 1991; Maurice et al., 1999; Nambu et al., 2000; Kita et al., 2004; Tachibana et al., 2008). The early excitation evoked in the GP and SNr by cortical stimulation is considered to be mediated by the cortico-STN-GP and cortico-STN$\mathrm{SNr}$ hyperdirect pathways, respectively. The inhibition in the GP and $\mathrm{SNr}$ is most likely mediated by the cortico-striato-GP and cortico-striato-SNr direct pathways, respectively. The late excitation in the GP and $\mathrm{SNr}$ is likely derived from the cortico-striatoGP-STN-GP and cortico-striato-GP-STN$\mathrm{SNr}$ indirect pathways, respectively. In the present study, the ablation of D2Rexpressing neurons in the striatum abolished inhibition in the GP and late excitation in the GP and SNr of the triphasic response evoked by cortical stimulation (Fig. 3, Fig. 4, Fig. 5, Table 2), supporting the above conclusion that the affected components are mediated by the striatopallidal projections.

Conversely, the ablation of cholinergic interneurons in the striatum had little effect on cortically evoked response patterns in GP and SNr neurons (Fig. 7, Table 3). Cholinergic interneurons receive glutamatergic inputs from the cerebral cortex and thalamus, and dopaminergic inputs from the substantia nigra pars compacta, and project to the MSNs to modulate their activity (Tepper and Bolam, 2004). Cortical inputs terminate at distal dendrites of cholinergic interneurons (Thomas et al., 2000), so the ablation of cholinergic interneurons may have limited effect on cortically 


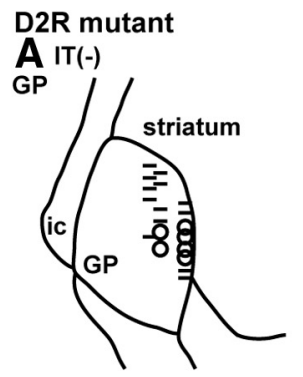

Bregma P 0.3

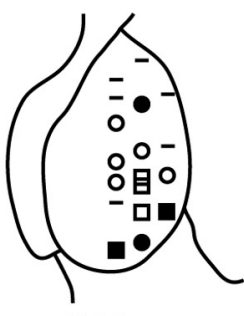

P 0.5

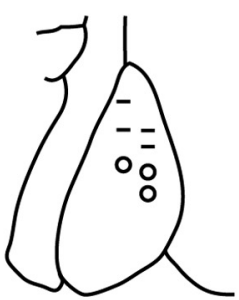

P 0.7
$\mathrm{SNr}$

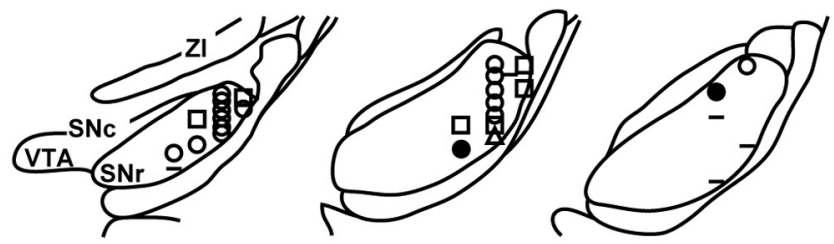

P 3.0
P 3.2
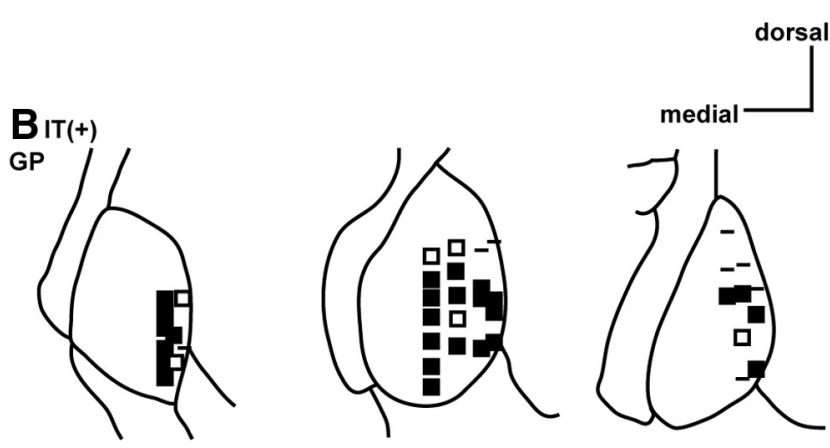

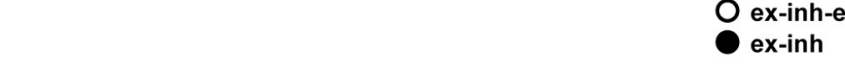
$\mathrm{SNr}$
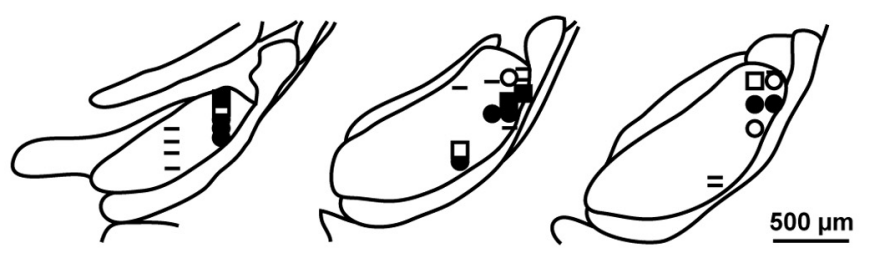

Figure 8. Locations of recorded neurons in the GP and SNr of a D2R mutant mouse. Locations of recorded neurons in the GP and SNr are shown in frontal sections before [IT( - ); $\boldsymbol{A}$ ] and after $[I T(+) ; \boldsymbol{B}]$ IT treatment in a D2R mutant mouse. Recorded neurons are indicated by different symbols according to the cortically evoked response patterns. Sections are arranged rostrocaudally from left to right and the distance from the bregma to each section is indicated. ic indicates internal capsule; SNc, substantia nigra pars compacta; VTA, ventral tegmental area; Zl, zona incerta.

evoked responses. In fact, cholinergic interneurons are related to reward and motor learning rather than to motor control itself (Aosaki et al., 1994; Kitabatake et al., 2003), and their ablation does not permanently affect behavior (Sano et al., 2003).

One criticism of the direct and indirect pathways model is that these two pathways cannot be clearly separated. Tracing studies of single striatal axons showed that MSNs projecting to the EPN and/or SNr, which are presumably direct pathway neurons, also had axon collaterals to the GP (Kawaguchi et al., 1990; Lévesque and Parent, 2005). Some MSNs express both D1Rs and D2Rs (Surmeier et al., 1996). However, in the present study, the cortically evoked inhibition in the $\mathrm{SNr}$, which is mediated by the striatonigral pathway, remained, whereas the cortically evoked inhibition in the GP, which is mediated by the striatopallidal pathway, was abolished after the ablation of D2R-expressing MSNs. Therefore, MSNs are approximately separated into D1R-expressing neurons projecting to the $\mathrm{SNr}$ and D2Rexpressing neurons projecting to the GP, and the axon terminals of D1R-expressing neurons in the GP are minor (if they exist at all) or are nonfunctional. Another possibility is that MSNs projecting to the GP in addition to the SNr express D2Rs, but not D1Rs.

\section{Functions of the striatopallidal indirect pathway}

The cortico-STN-SNr hyperdirect pathway conveys cortical excitation to the SNr with a short latency (Nambu et al., 2000, 2002). Combining the hyperdirect pathway with the classical direct and indirect pathways model, and considering the respective conduction velocity along each pathway, a dynamic version of the hyperdirect, direct, and indirect pathways model of the basal ganglia functions has been proposed (Mink and Thach, 1993; Hikosaka et al., 2000; Nambu et al., 2002; Fig. 9A). Signals through the cortico-STN-SNr hyperdirect pathway first excite the $\mathrm{SNr}$ and inhibit inappropriate movements. Next, signals through the corticostriato-SNr direct pathway inhibit the $\mathrm{SNr}$ and release appropriate movements, and finally, signals through the cortico-striato-GPSTN-SNr indirect pathway excite the SNr again and induce a clear termination of the movement released by the signals through the direct pathway. Therefore, the striatopallidal indirect pathway conveys "stop" signals to the target structures. This model can explain the results of the present study: the ablation of the striatopallidal indirect pathway diminished late excitation in the SNr and could not terminate movements, resulting in motor hyperactivity and contralateral rotations (Fig. 9B). Recently, concurrent activation of striatal direct and indirect pathways neurons during movements was reported (Cui et al., 2013), and this is compatible with this model. We hypothesize that cortical stimulation can mimic cortical activity during voluntary movements (Kita et al., 2004; Tachibana et al., 2008). Changes of the cortically evoked responses in the basal ganglia can explain the pathophysiology of hyperkinetic and hypokinetic movement disorders (Chiken et al., 2008; Kita and Kita, 2011; Nishibayashi et al., 2011). Future studies should further test this model by examining the motor-related activity during movements before and after IT treatment.

The present study also provides insights into the pathophysiology of movement disorders. In the early stage of HD, striatopallidal neurons in the indirect pathway are preferably affected compared with the striatonigral direct pathway neurons (Reiner et al., 1988). Therefore, the D2R mutant mouse in the present study can be considered as a model of early-stage HD. The static model of the basal ganglia function explains the pathophysiology of HD as follows: the loss of striatopallidal MSNs leads to reduced activity of the output nuclei through the indirect pathway and finally causes chorea (DeLong, 1990). However, neuronal recording from the GPe and GPi of HD patients during stereotactic surgery did not report such spontaneous activity changes (Tang et al., 2005; Starr et al., 2008). The present study suggests that the loss of the striatopallidal indirect pathway diminishes cortically evoked late excitation in the GPi/SNr without spontaneous activity changes and induces hyperactivity in HD. Indeed, the loss of late excitation was observed in the GP/EPN of dystonia model mice and in the GPe/GPi of a patient with dystonia, another hyperkinetic disorder (Chiken et al., 2008; Nishibayashi et al., 
A Normal state
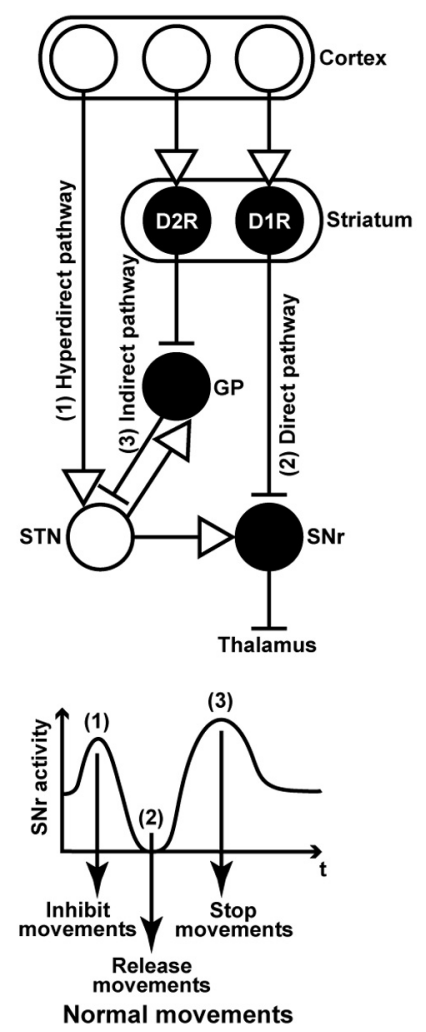

B Ablation of
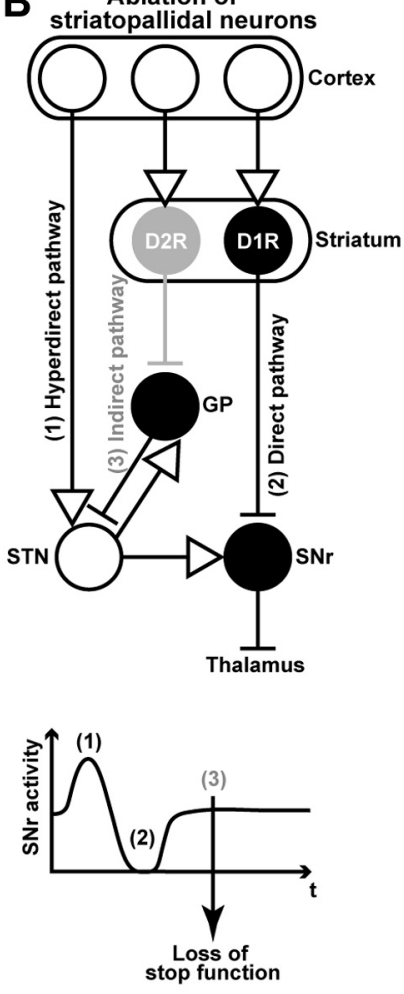

Motor hyperactivity

Figure 9. Schematic diagrams explaining motor hyperactivity after the ablation of the striatopallidal projections. $\boldsymbol{A}$, Normally, signals that originate in the cortex are first transmitted through the cortico-STN-SNr hyperdirect pathway, induce early excitation in the $\mathrm{SNr}$, and inhibit inappropriate movements [(1)]. Then, signals through the cortico-striato$\mathrm{SNr}$ direct pathway induce inhibition in the $\mathrm{SNr}$ and release appropriate movements [(2)]. Finally, signals through the cortico-striato-GP-STN-SNr indirect pathway induce late excitation in the $\mathrm{SNr}$ and stop movements [(3)]. $\boldsymbol{B}$, The ablation of striatopallidal neurons diminishes late excitation in the $\mathrm{SNr}$, so movements cannot be stopped, resulting in motor hyperactivity. White and black circles represent excitatory glutamatergic and inhibitory GABAergic neurons, respectively.

2011), and therefore, cortically driven dynamic activity, but not static activity of the basal ganglia, seems to be the key feature of their motor control functions.

\section{References}

Albin RL, Young AB, Penney JB (1989) The functional anatomy of basal ganglia disorders. Trends Neurosci 12:366-375. CrossRef Medline

Alexander GE, Crutcher MD (1990) Functional architecture of basal ganglia circuits: neural substrates of parallel processing. Trends Neurosci 13:266271. CrossRef Medline

Aosaki T, Tsubokawa H, Ishida A, Watanabe K, Graybiel AM, Kimura M (1994) Responses of tonically active neurons in the primate's striatum undergo systematic changes during behavioral sensorimotor conditioning. J Neurosci 14:3969-3984. Medline

Baik JH, Picetti R, Saiardi A, Thiriet G, Dierich A, Depaulis A, Le Meur M, Borrelli E (1995) Parkinsonian-like locomotor impairment in mice lacking dopamine D2 receptors. Nature 377:424-428. CrossRef Medline

Bateup HS, Santini E, Shen W, Birnbaum S, Valjent E, Surmeier DJ, Fisone G, Nestler EJ, Greengard P (2010) Distinct subclasses of medium spiny neurons differentially regulate striatal motor behaviors. Proc Natl Acad Sci U S A 107:14845-14850. CrossRef Medline

Chiken S, Shashidharan P, Nambu A (2008) Cortically evoked long-lasting inhibition of pallidal neurons in a transgenic mouse model of dystonia. J Neurosci 28:13967-13977. CrossRef Medline

Cui G, Jun SB, Jin X, Pham MD, Vogel SS, Lovinger DM, Costa RM (2013) Concurrent activation of striatal direct and indirect pathways during action initiation. Nature 494:238-242. CrossRef Medline

DeLong MR (1990) Primate models of movement disorders of basal ganglia origin. Trends Neurosci 13:281-285. CrossRef Medline

Franklin KBJ, Paxinos G (2008) The mouse brain in stereotaxic coordinates, Ed 3. New York: Academic.

Fujimoto K, Kita H (1992) Responses of rat substantia nigra pars reticulata units to cortical stimulation. Neurosci Lett 142:105-109. CrossRef Medline

Gerfen CR (1992) The neostriatal mosaic: multiple levels of compartmental organization in the basal ganglia. Annu Rev Neurosci 15:285-320. CrossRef Medline

Hikida T, Kaneko S, Isobe T, Kitabatake Y, Watanabe D, Pastan I, Nakanishi S (2001) Increased sensitivity to cocaine by cholinergic cell ablation in nucleus accumbens. Proc Natl Acad Sci U S A 98:13351-13354. CrossRef Medline

Hikida T, Kimura K, Wada N, Funabiki K, Nakanishi S (2010) Distinct roles of synaptic transmission in direct and indirect striatal pathways to reward and aversive behavior. Neuron 66:896-907. CrossRef Medline

Hikosaka O, Takikawa Y, Kawagoe R (2000) Role of the basal ganglia in the control of purposive saccadic eye movements. Physiol Rev 80:953-978. Medline

Hutchison WD, Allan RJ, Opitz H, Levy R, Dostrovsky JO, Lang AE, Lozano AM (1998) Neurophysiological identification of the subthalamic nucleus in surgery for Parkinson's disease. Ann Neurol 44:622-628. CrossRef Medline

Kaneko S, Hikida T, Watanabe D, Ichinose H, Nagatsu T, Kreitman RJ, Pastan I, Nakanishi S (2000) Synaptic integration mediated by striatal cholinergic interneurons in basal ganglia function. Science 289:633-637. CrossRef Medline

Kawaguchi Y, Wilson CJ, Emson PC (1990) Projection subtypes of rat neostriatal matrix cells revealed by intracellular injection of biocytin. J Neurosci 10:3421-3438. Medline

Kita H (1992) Responses of globus pallidus neurons to cortical stimulation: intracellular study in the rat. Brain Res 589:84-90. CrossRef Medline

Kita H, Kita T (2011) Cortical stimulation evokes abnormal responses in the dopamine-depleted rat basal ganglia. J Neurosci 31:10311-10322. CrossRef Medline

Kita H, Nambu A, Kaneda K, Tachibana Y, Takada M (2004) Role of ionotropic glutamatergic and GABAergic inputs on the firing activity of neurons in the external pallidum in awake monkeys. J Neurophysiol 92:3069 3084. CrossRef Medline

Kitabatake Y, Hikida T, Watanabe D, Pastan I, Nakanishi S (2003) Impairment of reward-related learning by cholinergic cell ablation in the striatum. Proc Natl Acad Sci U S A 100:7965-7970. CrossRef Medline

Kitano H, Tanibuchi I, Jinnai K (1998) The distribution of neurons in the substantia nigra pars reticulata with input from the motor, premotor and prefrontal areas of the cerebral cortex in monkeys. Brain Res 784:228238. CrossRef Medline

Kobayashi K, Morita S, Sawada H, Mizuguchi T, Yamada K, Nagatsu I, Fujita K, Kreitman RJ, Pastan I, Nagatsu T (1995) Immunotoxin-mediated conditional disruption of specific neurons in transgenic mice. Proc Nat Acad Sci U S A 92:1132-1136. CrossRef Medline

Kravitz AV, Freeze BS, Parker PR, Kay K, Thwin MT, Deisseroth K, Kreitzer AC (2010) Regulation of parkinsonian motor behaviours by optogenetic control of basal ganglia circuitry. Nature 466:622-626. CrossRef Medline

Kreitzer AC, Berke JD (2011) Investigating striatal function through celltype-specific manipulations. Neuroscience 198:19-26. CrossRef Medline

Legéndy CR, Salcman M (1985) Bursts and recurrences of bursts in the spike trains of spontaneously active striate cortex neurons. J Neurophysiol 53: 926-939. Medline

Lévesque M, Parent A (2005) The striatofugal fiber system in primates: a reevaluation of its organization based on single-axon tracing studies. Proc Natl Acad Sci U S A 102:11888-11893. CrossRef Medline

Maurice N, Deniau JM, Glowinski J, Thierry AM (1999) Relationships between the prefrontal cortex and the basal ganglia in the rat: physiology of the cortico-nigral circuits. J Neurosci 19:4674-4681. Medline

Mink JW, Thach WT (1993) Basal ganglia intrinsic circuits and their role in behavior. Curr Opin Neurobiol 3:950-957. CrossRef Medline

Nambu A, Tokuno H, Hamada I, Kita H, Imanishi M, Akazawa T, Ikeuchi Y, Hasegawa N (2000) Excitatory cortical inputs to pallidal neurons via the subthalamic nucleus in the monkey. J Neurophysiol 84:289-300. Medline Nambu A, Tokuno H, Takada M (2002) Functional significance of the 
cortico-subthalamo-pallidal 'hyperdirect' pathway. Neurosci Res 43: 111-117. CrossRef Medline

Nishibayashi H, Ogura M, Kakishita K, Tanaka S, Tachibana Y, Nambu A, Kita H, Itakura T (2011) Cortically evoked responses of human pallidal neurons recorded during stereotactic neurosurgery. Mov Disord 26:469476. CrossRef Medline

Obeso JA, Rodríguez-Oroz MC, Rodríguez M, Lanciego JL, Artieda J, Gonzalo N, Olanow CW (2000) Pathophysiology of the basal ganglia in Parkinson's disease. Trends Neurosci 23:S8-19. CrossRef Medline

Reiner A, Albin RL, Anderson KD, D'Amato CJ, Penney JB, Young AB (1988) Differential loss of striatal projection neurons in Huntington disease. Proc Natl Acad Sci U S A 85:5733-5737. CrossRef Medline

Ryan LJ, Clark KB (1991) The role of the subthalamic nucleus in the response of globus pallidus neurons to stimulation of the prelimbic and agranular frontal cortices in rats. Exp Brain Res 86:641-651. Medline

Sano H, Yasoshima Y, Matsushita N, Kaneko T, Kohno K, Pastan I, Kobayashi K (2003) Conditional ablation of striatal neuronal types containing dopamine D2 receptor disturbs coordination of basal ganglia function. J Neurosci 23:9078-9088. Medline

Sieradzan KA, Mann DM (2001) The selective vulnerability of nerve cells in Huntington's disease. Neuropathol Appl Neurobiol 27:1-21. CrossRef Medline

Starr PA, Kang GA, Heath S, Shimamoto S, Turner RS (2008) Pallidal neuronal discharge in Huntington's disease: support for selective loss of striatal cells originating the indirect pathway. Exp Neurol 211:227-233. CrossRef Medline
Surmeier DJ, Song WJ, Yan Z (1996) Coordinated expression of dopamine receptors in neostriatal medium spiny neurons. J Neurosci 16 : 6579-6591. Medline

Tachibana Y, Kita H, Chiken S, Takada M, Nambu A (2008) Motor cortical control of internal pallidal activity through glutamatergic and GABAergic inputs in awake monkeys. Eur J Neurosci 27:238-253. CrossRef Medline

Tang JK, Moro E, Lozano AM, Lang AE, Hutchison WD, Mahant N, Dostrovsky JO (2005) Firing rates of pallidal neurons are similar in Huntington's and Parkinson's disease patients. Exp Brain Res 166: 230-236. CrossRef Medline

Tepper JM, Bolam JP (2004) Functional diversity and specificity of neostriatal interneurons. Curr Opin Neurobiol 14:685-692. CrossRef Medline

Thomas TM, Smith Y, Levey AI, Hersch SM (2000) Cortical inputs to m2immunoreactive striatal interneurons in rat and monkey. Synapse 37: 252-261. Medline

Xu M, Moratalla R, Gold LH, Hiroi N, Koob GF, Graybiel AM, Tonegawa S (1994) Dopamine D1 receptor mutant mice are deficient in striatal expression of dynorphin and in dopamine-mediated behavioral responses. Cell 79:729-742. CrossRef Medline

Yoshida S, Nambu A, Jinnai K (1993) The distribution of the globus pallidus neurons with input from various cortical areas in the monkeys. Brain Res 611:170-174. CrossRef Medline

Yung KK, Bolam JP, Smith AD, Hersch SM, Ciliax BJ, Levey AI (1995) Immunocytochemical localization of D1 and D2 dopamine receptors in the basal ganglia of the rat: light and electron microscopy. Neuroscience 65: 709-730. CrossRef Medline 